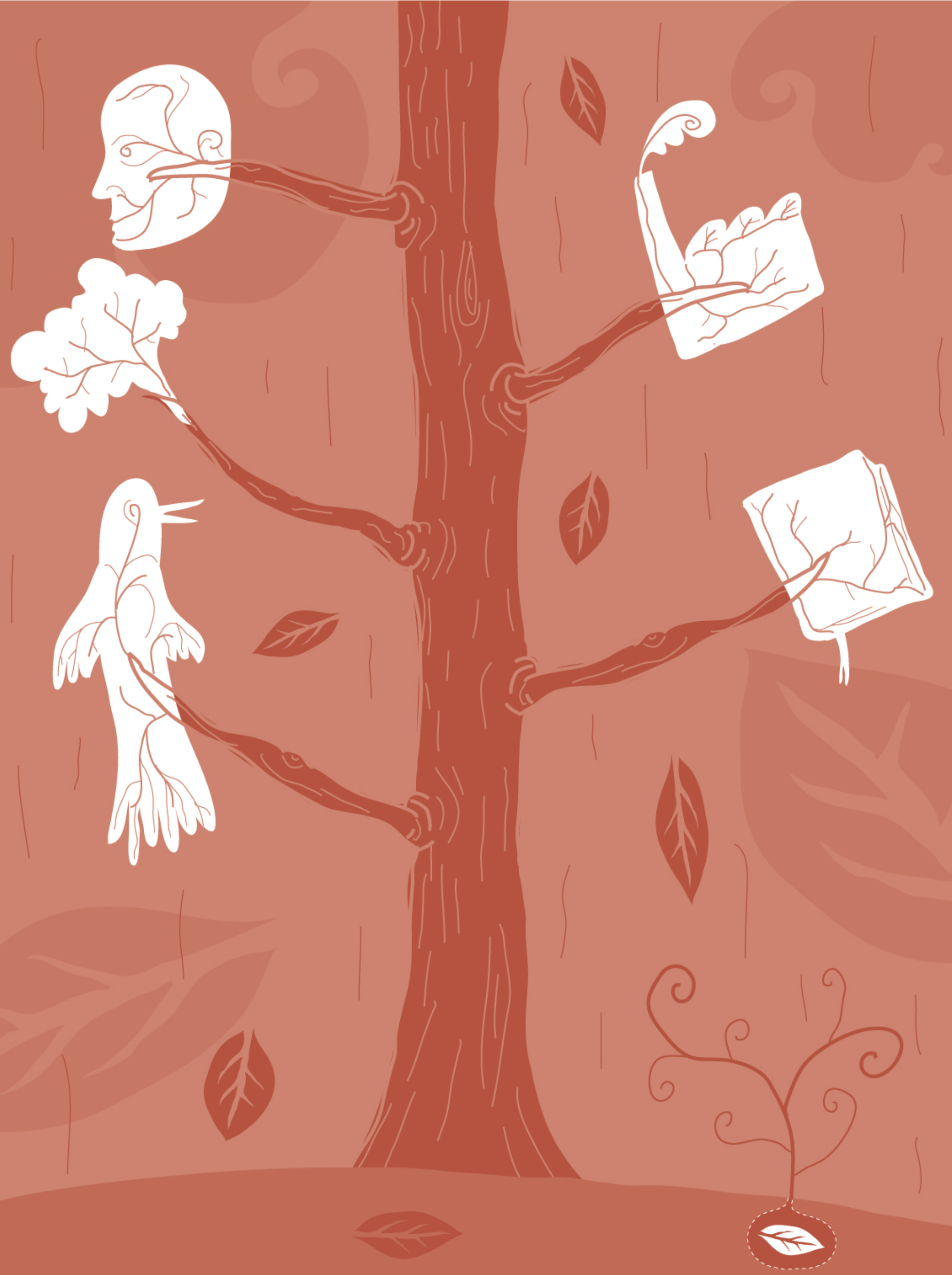




\section{Relações Públicas na gestão da responsabilidade social: desafio e oportunidade}

Maria José da Costa Oliveira

- Doutora e Mestre em Ciências da Comunicação pela Escola de Comunicações e Artes da Universidade de São Paulo (ECA-USP)

- Especialista em Administração de Marketing pela Universidade São Judas

- Bacharel em Relações Públicas pela Universidade de Mogi das Cruzes

- Coordenadora dos cursos de graduação em Relações Públicas e Publicidade e Propaganda e do curso de pós-graduação lato sensu em Comunicação Pública e Responsabilidade Social das Faculdades Metropolitanas de Campinas (Metrocamp)

- Consultora em Gestão da Comunicação Pública na Mendes \& Nader Comunicação e Responsabilidade Social

- Organizadora do livro Comunicação Pública. Campinas: Alínea, 2004. 208 p.

-zezecoliveira@gmail.com

Silvana Nader

- MBA em Gestão e Empreendedorismo Social pela Fundação Instituto de Administração da Universidade de São Paulo (FIA-USP)

- Especialista em Marketing pela Fundação Getúlio Vargas (FGV)

- Bacharel em Relações Públicas pela Escola de Comunicações e Artes da Universidade de São Paulo (ECA-USP)

- Docente de graduação e pós-graduação das Faculdades Metropolitanas de Campinas (Metrocamp) e do curso de Gestão do Terceiro Setor da Escola Superior de Advocacia da Ordem dos Advogados do Brasil de São Paulo (OAB-SP)

- Sócia-diretora da Mendes \& Nader Comunicação e Responsabilidade Social

- silvana@mendes-nader.com.br 


\section{Resumo}

O artigo tem o propósito de analisar o papel da área de Relações Públicas na gestão da responsabilidade social. Enfatiza-se, de início, o novo posicionamento das organizações frente às transformações que vêm ocorrendo na sociedade e a relevância de manter relacionamentos estratégicos com os diversos públicos como base para o estabelecimento de políticas de responsabilidade social. Enfatiza-se, ainda, a necessidade do profissional de Relações Públicas entender e assumir seu papel na gestão estratégica das políticas de responsabilidade social, visando ao alinhamento e equilíbrio entre os interesses da sociedade, das organizações e, principalmente, ao exercício da cidadania.

PALAVRAS-CHAVE: RELAÇÕES PÚBLICAS • POLÍTICA DE RESPONSABILIDADE SOCIAL • GESTÃo ESTRATÉGICA

\section{Abstract}

The article analyzes the role of the area of Public Relations in social responsibility management. It starts by emphasizing the new positioning of the organizations in the light of the transformations that are occurring in society and the relevance of maintaining strategic relationships with the different publics as base for establishing social responsibility policies. It also stresses Public Relations professional's need to understand and to assume his/her role in the strategic management of the social responsibility policies, with the aim of alignment and equilibrium between the interests of the society, of the organizations and, particularly, exercise of citizenship.

KEYWORDS: PUBLIC RELATIONS • POLITICS OF SOCIAL RESPONSIBILITY • STRATEGIC MANAGEMENT

\section{Resumen}

El artículo tiene el propósito de analizar el papel del área de Relaciones Públicas en la gestión de la responsabilidad social. Se enfatizan, inicialmente, el nuevo posicionamiento de las organizaciones frente a las transformaciones que están ocurriendo en la sociedad y la relevancia de mantener relaciones estratégicas con los diversos públicos como base para el establecimiento de políticas de responsabilidad social. Se destaca, asimismo, la necesidad de que el profesional de Relaciones Públicas entienda y asuma su papel en la gestión estratégica de las políticas de responsabilidad social, buscando el alineamiento y el equilibrio entre los intereses de la sociedad, de las organizaciones y, sobre todo, el ejercicio de la ciudadanía.

PALABRAS CLAVE: RELACIONES PÚBLICAS • POLÍTICA DE RESPONSABILIDAD SOCIAL • GESTIÓN ESTRATÉGICA 
$\mathrm{F}$ azendo uma análise sobre a formação do profissional de Relações Públicas, podemos identificar nos currículos dos diversos cursos no Brasil uma preocupação não só com a formação técnica, mas também com a formação humanística que, de maneira geral, é constituída por disciplinas que versam sobre Filosofia, Sociologia, Cultura brasileira, Antropologia Cultural, realidade brasileira, Ciência Política e outras que reforçam o caráter multidisciplinar da área.

Entretanto, mesmo com tal currículo, percebe-se que a atuação do profissional de Relações Públicas, salvo algumas exceções, ainda tem se restringido ao operacional, prescindindo de uma performance estratégica que contemple não só uma análise do micro ambiente das organizações, mas, principalmente, que atente para o macro ambiente social, político, econômico e ambiental.

As empresas e outras formas de organização são constituídas por pessoas, para pessoas e estão inseridas num cenário mercadológico e social que exige gestores capazes de instituir políticas de relacionamento estratégico, pois todos os processos existentes nas empresas dependem do comprometimento daqueles com elas direta ou indiretamente envolvidos. E isso se torna mais relevante quando se trata da gestão de políticas de responsabilidade social.

Porém, resta saber se os profissionais de Relações Públicas têm consciência e estão preparados para assumir o papel de gestores estratégicos capazes de realizar análises micro e macro ambientais, entender a evolução da sociedade, questões internacionais ou políticas públicas. Será que conhecem a complexidade dos negócios da empresa, comportamento e tendências do mercado mundial, regional e local onde ela atua? Estão preparados para fazer o alinhamento de todos estes aspectos dentro de um planejamento? Serão capazes de analisar, criticar e inserir as atividades de Relações Públicas neste contexto?

O papel de gestores da responsabilidade social pode ser assumido por profissionais de Relações Públicas, desde que estejam devidamente preparados para os desafios que se lhes apresentam, afinal, política de responsabilidade social não se restringe apenas a ações pontuais junto à comunidade, mas a um processo de tomada de decisão baseado nos valores organizacionais e em esforços sistemáticos e contínuos para atingir seus objetivos de negócios em conjunto com os objetivos sociais.

Vejamos, portanto, alguns aspectos importantes que norteiam a análise que se pretende aqui apresentar. 
RELACÕ̃ES PÚBLICAS NA GESTÃO DA RESPONSABILIDADE SOCIAL: DESAFIO

E OPORTUNIDADE - MARIA JOSÉ DA COSTA OLIVEIRA • SILVANA NADER

\section{Um cenário em transformação}

A partir da segunda metade do século XX, o Brasil passou por grandes transformações em função da modernização de suas bases de desenvolvimento. Tais transformações provocaram profundos impactos junto à sociedade e ao meio ambiente.

Segundo o relatório Nosso Futuro Comum (1988), publicado pela Comissão Mundial Sobre Meio Ambiente e Desenvolvimento, o processo de transformação desenvolvimentista ocorrido no Brasil trouxe êxitos como queda da mortalidade infantil, aumento da expectativa de vida, aumento crescente do percentual de adultos que sabem ler e escrever e de crianças ingressando nas escolas.

Entretanto, os mesmos processos que provocaram melhorias em escala global também geraram impactos preocupantes, tais como demanda crescente por energia e por recursos naturais, aumento da poluição em todas as suas formas e mudanças climáticas, aumento da pobreza, da exclusão e das desigualdades sociais.

A tomada de consciência dessa situação nos impinge a reconhecer as causas e assumir nosso papel como cidadãos, buscando encontrar novos rumos para esse processo já desencadeado e que coloca em risco o que o filósofo e teólogo Leonardo Boff chama de sonho civilizacional: "Temos que reconstruir a casa humana comum - a Terra para que nela todos possam caber. Urge modelá-la de tal forma que tenha sustentabilidade para alimentar um novo sonho civilizacional” (BOFF, 1999, p. 27).

Em relação à desintegração sócio-ambiental que vivenciamos, Capra, já em 1982, nos alertava para os crescentes problemas sociais que, hoje, em muitos casos, só se agravaram. Nesse sentido, ele afirma:

"Existem numerosos sinais de desintegração social, incluindo recrudescimento de crimes violentos, acidentes e suicídios; o aumento do alcoolismo e do consumo de drogas; e um número crescente de crianças com deficiência de aprendizagem e distúrbios de comportamento. (...) A par dessas patologias sociais, temos presenciado anomalias econômicas que parecem confundir nossos principais economistas e politicos. Inflação galopante, desemprego maciço e uma distribuição grosseiramente desigual da renda e da riqueza passaram a ser características estruturais da maioria das economias nacionais." (CAPRA, 1982, p. 22)

Diante do panorama exposto, uma transformação social torna-se necessária, principalmente com a participação dos diversos setores da sociedade, incluindo-se as empresas, que tendem a assumir novas responsabilidades frente aos problemas que se lhes apresentam. 
Capra também reforça essa noção ao afirmar que "uma resolução só poderá ser implementada se a estrutura da própria teia for mudada, o que envolverá transformações profundas em nossas instituições sociais, em nossos valores e idéias” (1982, p. 23).

Em 1505, Niccolò Machiavelli já dissertava em O Príncipe ${ }^{1}$ sobre as dificuldades e os desafios implícitos na introdução de qualquer tipo de mudança. E ao discorrermos sobre mudanças, verificamos que no mundo inteiro o papel social e a responsabilidade do indivíduo estão sendo revistos numa velocidade bastante expressiva.

A liberdade, o fortalecimento democrático e a era da informação fomentam a mobilização das pessoas em torno de questões de interesse público e coletivo, como direitos humanos, preservação ambiental, inclusão social, entre outros.

Como conseqüência direta desse movimento, aumentam as cobranças de toda a sociedade sobre o Estado e sobre o setor privado para uma resposta efetiva às mudanças e impactos provocados pelo crescimento acelerado.

\section{Relacionamentos estratégicos - base para a política de responsabilidade social}

Tais transformações na sociedade estão levando ao surgimento de novos modelos e conceitos de organização e de negócios que são parte de um contexto e de uma complexidade jamais vistos.

Para Magreta (2002), projetar uma organização é um exercício de frustração:

"[...] O tempo e os acontecimentos inevitavelmente sobrepujam o plano mais elaborado. De uma ou de outra forma você terá de ultrapassar o projeto. Você vai apagar aqui, redesenhar ali, e como o todo é um sistema complexo, uma mudança em um local surgirá como uma conseqüência imprevista em outro lugar. As organizações estão sempre saindo de alinhamento [...]."

A organização (pública, privada ou do terceiro setor) é um sistema aberto que interage no ambiente onde está inserida, atuando, influenciando e, paralelamente, reagindo e sendo influenciada, provocando mudanças, mas ao mesmo tempo se adaptando a elas. Para isso, precisa adquirir a mobilidade, a flexibilidade e a competência necessárias ao relacionamento com os diversos públicos que emergem ou se reestruturam no novo cenário.

1 O Príncipe foi escrito em 1505 e publicado em 1515. Fonte digital Edição Ridendo Castigat Mores. Disponível em: <http://www.ebookbrasil.org> Acesso em 2007. 
RELACÕ̃ES PÚBLICAS NA GESTÃO DA RESPONSABILIDADE SOCIAL: DESAFIO E OPORTUNIDADE • MARIA JOSÉ DA COSTA OLIVEIRA • SILVANA NADER

Cada organização tem seus públicos específicos, estratégicos, alvo, hoje denominados stakeholders. São grupos, pessoas, entidades, instituições, movimentos com algum tipo de relação com a organização, seja por pertencerem a ela, ou por haver nesta relação interesses mútuos ou, ainda, por afetarem ou serem afetados direta ou indiretamente por suas atividades, mas sempre gerando e demandando expectativas. É o suficiente para que passem a exercer algum tipo de influência nas decisões, estratégias, formas de gestão e atuação da organização.

O relacionamento com tais públicos não é exatamente uma tarefa simples, já que é natural que haja conflitos, posicionamentos contraditórios e até incompatíveis dentro dessa diversidade. No caso da iniciativa privada, no passado considerada fonte de progresso e geradora de riquezas, hoje é cobrada pelo custo social advindo do seu desenvolvimento.

Como resposta, segundo Kunsch (2003, p. 40), "as organizações estão bastante preocupadas com sua dimensão social, haja vista os enunciados de sua missão, sua visão e seus valores". Elas tentam demonstrar que não são apenas unidades econômicas, mas também unidades sociais.

Para Hélio Mattar (2003), presidente do Instituto $\mathrm{Akatu}^{2}$, a grande mudança está em sair da era do produto para a era das relações:

"A grande mudança é sair da época do paradigma do produto e entrar na época do paradigma das relações - com funcionários, fornecedores, consumidores, meio ambiente, comunidade, governo, concorrentes, sindicatos e a sociedade. Isso tem muito a evoluir em todas as partes do mundo."

Essa evolução passa, em especial, pela ética nos negócios. Conforme Robert Srour (2000, p. 41), as "decisões das empresas carregam um enorme poder de irradiação pelos efeitos que provocam". Ele também afirma que estes efeitos atingem os ambientes interno e externo da organização em função da vulnerabilidade dos agentes sociais.

É o momento de relações focadas na transparência, responsabilidade e probidade, tanto no trato das questões públicas, no caso do governo, como no relacionamento com toda a cadeia produtiva, no caso das empresas.

A atuação responsável, eficaz, transparente e ética da organização pode gerar ganhos que inevitavelmente afetam de maneira positiva os seus negócios. As marcas e a reputação são ativos preciosos das empresas que levam tempo e grandes investimentos para serem construídas num ambiente competitivo de mercado. A perda da credibili-

2 O Instituto Akatu é uma organização não-governamental sem fins lucrativos criada para educar e mobilizar a sociedade para o consumo consciente. 
RELAÇÕES PÚBLICAS NA GESTÃO DA RESPONSABILIDADE SOCIAL: DESAFIO E OPORTUNIDADE • MARIA JOSÉ DA COSTA OLIVEIRA • SILVANA NADER

dade pela falta de transparência ou ética na condução dos negócios pode ser fatal para uma organização.

A responsabilidade social deve refletir os valores intrínsecos da administração, traduzidos por Mcintosh, Leipziger, Jones e Colemam (2001) como sendo a "cidadania no coração do planejamento estratégico". Agindo assim, a empresa socialmente responsável tem um comprometimento perene e duradouro que vai influir de forma decisiva na sustentabilidade e na longevidade de seus negócios e, principalmente, contribuir para que tenhamos nosso sonho civilizacional realizado: desenvolvimento econômico e social com respeito ao meio ambiente.

A preocupação com as questões sociais por parte das empresas existe ao considerarmos que as empresas dependem, cada vez mais, da autorização da sociedade para poderem atuar. Austin $(2004)^{3}$ descreve o que tem, por exemplo, acontecido nos Estados Unidos nos últimos dez anos:

"O que tem acontecido (...) é um aumento de percepção sobre a importância da relação entre negócio e sociedade. (...) As pesquisas mostram que a maioria das pessoas espera que as empresas ajam não só de acordo com princípios éticos, mas que também contribuam para o desenvolvimento social. Elas também indicam que, se uma empresa não se engaja socialmente, as pessoas estão prontas a puni-la, seja não trabalhando para ela, seja não comprando os seus produtos."

É interessante observar o impacto positivo das políticas de responsabilidade social de empresas junto à sociedade, pois, conforme Austin:

"O contrário também acontece: quando uma empresa ganha a reputação de ser socialmente responsável, ela atrai executivos mais talentosos e estes ficam mais tempo nesse emprego - ou seja, há vantagens de recrutamento e retenção de profissionais. Quanto aos consumidores, as pesquisas mostram que, diante de dois produtos de mesmo preço e qualidade, eles tendem a escolher aquele ligado a uma empresa cuja imagem está ligada ao social. A outra força vem da relação entre empresa e governo. Quando este tem a percepção de que a companhia tem um valor social e que o está ajudando a cumprir o seu papel, o tratamento oficial melhora."

Atualmente, muitas empresas reconhecem que o valor social transformou-se em estratégia de negócio. Para Austin, "o grande desafio é criar uma sinergia entre a área comercial e a área social da empresa”. Assim, olhar o social como setor estratégico é fundamental e exige gestores com capacidade de entender a sociedade, o mercado, as questões mundiais, regionais e locais.

3 James Austin é titular da cátedra Snider Professorship of Business Administration da Harvard Business School, em Boston, e co-fundador da Social Enterprise Knowledge Network (SEKN). 
RELAÇ̃̃ES PÚBLICAS NA GESTÃO DA RESPONSABILIDADE SOCIAL: DESAFIO E OPORTUNIDADE - MARIA JOSÉ DA COSTA OLIVEIRA • SILVANA NADER

Austin (2004) destaca os estágios de colaboração entre empresa e sociedade, enfatizando o estágio filantrópico, que é a maneira tradicional pela qual se relacionaram durante muito tempo empresas e organizações não-governamentais (ONGs). A iniciativa, em geral, é da ONG, que pede essa colaboração à companhia.

No estágio transacional, empresas e ONGs começam a pensar juntas em ações e projetos que são muito bem definidos, e a troca de valores é bilateral. A companhia deixa de só dar dinheiro e passa a mobilizar outras habilidades e competências. Assim como a empresa pode entrar com sua expertise em um projeto das organizações sociais, o contrário também pode acontecer. No transacional, estão os patrocínios e os projetos em que a marca da ONG se agrega à marca da empresa.

No estágio integrativo, as missões, valores e estratégias das empresas e das organizações da sociedade civil convergem ainda mais. Ambas usam suas competências centrais nos projetos, aquelas que garantem seu sucesso individualmente. E elas combinam essas características para criar novas atividades e um novo valor. As ações sociais tornam-se estratégicas para os dois parceiros e otimizam os recursos envolvidos; uma espécie de joint venture, e não uma simples transação pontual. Uma relação efetiva e duradoura gera impactos e resultados sociais mais efetivos.

\section{Relações Públicas e a responsabilidade social}

Abordar Relações Públicas na gestão da responsabilidade social, como podemos depreender do que foi até aqui apresentado, parece uma proposta natural, tendo em vista a importância dos relacionamentos estratégicos que as organizações precisam instituir com diferentes públicos para a efetivação de uma política de responsabilidade social que esteja, conforme Austin (2004), preferencialmente, entre o estágio transacional e o integrativo.

Vale lembrar que Relações Públicas, como uma atividade voltada ao equilíbrio entre os interesses de organizações e seus públicos, tem diante de si um cenário social, político e econômico que exige seu posicionamento claro na assessoria às organizações sobre o papel social que devem desempenhar, visando colaborar com as ações de in-

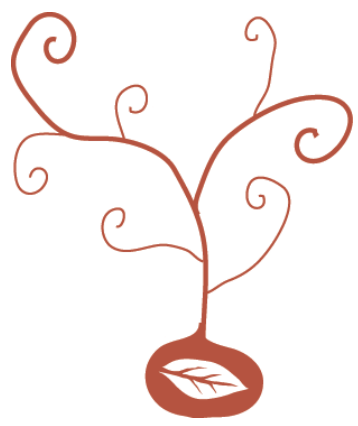
teresse público.

As transformações que vêm ocorrendo na sociedade precisam se refletir nas políticas e ações de Relações Públicas, expressas em nível macro e micro ambiental, contribuindo com o exercício da cidadania e com a valorização crescente da relação de transparência, responsabilidade social, diálogo e confiança que se deve buscar entre organizações e públicos. E é agindo assim que as Relações Públicas podem ser consideradas uma função intimamente ligada à educação com fim social, porque se propõem, justamente, a estabelecer a relação entre organização e públicos de forma consciente e ética. 
Mesmo Andrade (1989), precursor do conceito de público em Relações Públicas no Brasil, já identificava o implícito papel educativo da área ao considerar que o grupo denominado como público deve receber informações qualificadas e constantes, ter a oportunidade de debate que inclui as controvérsias e a busca de consenso. Tais características estão presentes no processo educativo, que tem como uma das alternativas para sua efetivação a gestão do conhecimento e é base para que se consolide a democracia.

Assim, na função de formar públicos, identificá-los e manter com eles uma relação de aproximação, de transparência, de ética, de confiança, as Relações Públicas contribuem com o exercício da cidadania, da democracia e deixam clara a relevância de seu papel na gestão da responsabilidade social.

Essa afirmação é confirmada ao resgatarmos os indicadores de responsabilidade social apresentados pelo Instituto Ethos ${ }^{4}$, que incluem: valores e transparência; relacionamento com o público interno; gerenciamento do impacto ambiental; relação com fornecedores, consumidores e comunidade local, bem como relação com o governo e sociedade, com transparência política e liderança social.

As Relações Públicas mantêm interface com outras áreas envolvidas com a educação com fim social, contribuindo com a valorização das parcerias, as iniciativas cidadãs, as campanhas de solidariedade, a busca da justiça social e a qualidade de vida.

Estabelece -se, então, uma relação de causa e efeito entre as ações de impacto social e o processo de democratização e cidadania, levando não só as organizações de primeiro e segundo setores, como também as associações civis a buscarem uma interlocução com os diferentes públicos.

Entretanto, para que as Relações Públicas tenham uma atuação determinante e contribuam efetivamente com a instituição da cidadania, assessorando o desenvolvimento de uma política de responsabilidade social por parte das organizações que representam e, mais do que isso, sendo capazes de colaborar para a instituição de uma ação integrada envolvendo os diferentes setores, as chamadas alianças intersetoriais (FISHER, 2002), é preciso que se estabeleça um consenso em torno de sua inerente responsabilidade nesse sentido.

Os profissionais, ao assumirem sua parte no processo de edificação de uma sociedade sustentável, devem adotar uma postura proativa em que as virtudes sociais começam a ser incorporadas às políticas organizacionais e cuja transparência já não parece tão utópica quanto há alguns anos.

4 O Instituto Ethos de Empresas e Responsabilidade Social é uma associação sem fins lucrativos criada com a missão de mobilizar, sensibilizar e ajudar as empresas a gerir seus negócios de forma socialmente responsável. 
RELACÕ̃ES PÚBLICAS NA GESTÃO DA RESPONSABILIDADE SOCIAL: DESAFIO E OPORTUNIDADE • MARIA JOSÉ DA COSTA OLIVEIRA • SILVANA NADER

Pode-se alegar que a empresa só investe em políticas sociais e ambientais em função de sua expectativa de obter retorno, como, por exemplo, o fortalecimento da imagem e da marca, a preferência dos consumidores e a melhoria do ambiente interno (ainda que não seja um ganho exclusivamente mercadológico e imediato).

A divulgação dos investimentos realizados e dos benefícios dos projetos junto à mídia e à sociedade pode ser considerada absolutamente legítima, desde que seja realizada de forma ética e com o objetivo de disseminar boas práticas e não somente buscar a visibilidade.

Mas as atividades de Relações Públicas vão muito além da comunicação em sua essência. Por ser uma área ligada à educação com fim social que busca o equilíbrio nas relações sociais entre a organização e seus públicos, as Relações Públicas têm importante papel ao colaborar com a instituição de políticas públicas, ao definir as políticas sociais internas envolvendo seus diferentes públicos para que assumam o papel de agentes de transformação social.

\section{Considerações finais}

A gestão da responsabilidade social exige profissionais com formação humanística e técnica, com visão estratégica, liderança e espírito empreendedor, que se adaptem ao dinâmico sistema organizacional, mas que, principalmente, tenham visão social e comprometimento com a causa, para sensibilizar, motivar, convencer, aglutinar e gerar atitude.

Entretanto, para que cumpram com sua função de educação com fim social e gestão de políticas de responsabilidade social, os profissionais de Relações Públicas necessitam se adaptar a um cenário complexo e dinâmico, em constante transformação.

Em nossa história recente, podemos identificar alguns temas que marcaram a gestão das organizações modernas, entre eles: qualidade dos produtos, reengenharia, valorização do público interno e do consumidor, ecologia, integração com a comunidade, ética nos negócios e alianças intersetoriais.

Atualmente, todos esses temas permeiam as políticas de responsabilidade social das organizações e, para que os profissionais de Relações Públicas assumam a gestão desse processo, é preciso que percebam sua magnitude e a rapidez com que está se firmando.

A área de Relações Públicas dará uma resposta à atual demanda da sociedade, com o aprimoramento na formação de seus profissionais, visando prepará-los para que reúnam as competências sociais e técnicas e assumam o papel de gestores da responsabi- 
RELAÇÕES PÚBLICAS NA GESTÃO DA RESPONSABILIDADE SOCIAL: DESAFIO

E OPORTUNIDADE • MARIA JOSÉ DA COSTA OLIVEIRA • SILVANA NADER

lidade social e, principalmente, fomentem o exercício da cidadania e a consolidação da democracia.

\section{Bibliografia}

ANDRADE, Cândido Teobaldo de Souza. Psico-sociologia das relações públicas. 2.ed. São Paulo: Loyola, 1989.

AUSTIN, James. Como unir estratégia e responsabilidade social nos negócios. Valor

Econômico, São Paulo, 19 mai. 2004. Carreira.

BOFF, Leonardo. Saber cuidar: ética do humano, compaixão pela terra. Rio de Janeiro: Editora Vozes, 1999.

CAPRA, Fritjof. O ponto de mutação: a ciência, a sociedade e a cultura emergente. São Paulo: Editora Cultrix, 1982.

FISCHER, Rosa Maria. O desafio da colaboração: práticas de responsabilidade social entre empresas e terceiro setor. São Paulo: Editora Gente, 2002.

KUNSCH, Margarida M. Krohling. Planejamento de relações públicas na comunicação integrada. 4.ed. rev., atual. e ampl. São Paulo: Summus, 2003.

. Relações públicas e modernidade: novos paradigmas na comunicação organizacional. São Paulo: Summus, 1997.

MAGRETA, Joan. O que é gerenciar e administrar. Rio de Janeiro: Campus, 2002. (Tradução Hugo Melo).

MATTAR, Hélio. Responsabilidade social e consumo consciente. MBA Gestão e Empreendedorismo Social - FIA. São Paulo: Universidade de São Paulo, 2003.

MCINTOSH, M. et al. Cidadania corporativa: estratégias bem sucedidas para empresas responsáveis. Rio de Janeiro: Qualitymark, 2001. (Tradução Bazán Tecnologia e Lingüística)

NADER, S. M.; SETA FILHO, J.; CALIXTO FILHO, J. Complexidade e desafios da responsabilidade socioambiental na indústria de risco. TCC- MBA Gestão e Empreendedorismo Social - FIA. São Paulo: Universidade de São Paulo, 2004.

NOSSO Futuro Comum. Rio de Janeiro: Editora Fundação Getúlio Vargas,1988. (CMMAD: Comissão Mundial sobre Meio Ambiente e Desenvolvimento - ONU)

OLIVEIRA, Maria José da Costa. A relação do estado, da sociedade e do mercado na construção da cidadania: o papel das relações públicas. Tese de Doutorado - Escola de Comunicações e Artes. São Paulo: Universidade de São Paulo, 2001.

SROUR, Robert Henry. Ética empresarial. 2.ed. São Paulo: CAMPUS, 2000.

Internet

Business For Social Responsability. Disponível em: <http://www.bsr.org>

Instituto Ethos de Responsabilidade Social. Disponível em: <http://www.ethos.org.br>

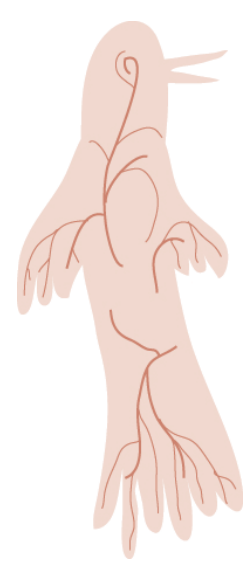

ANO $3 \cdot$ NÚMERO $5 \cdot 2^{\circ}$ SEMESTRE DE $2006 \cdot$ organicom • 107 